\title{
An Exceptional Case of Gestational Gigantomastia
}

Gulijimila Adili ${ }^{1}$, Aximujiang Axier ${ }^{2}$, Luan Meixiang, Guo Chenming ${ }^{1 *}$, Li Huifang ${ }^{1}$, Gulizila Keyoumu ${ }^{1}$, Aimureguli Yusan ${ }^{1}$, Cui Yajing ${ }^{1}$, Outikuer Aini ${ }^{1}$, Wang Dandan ${ }^{1}$ and Dilimulati Aisimutula ${ }^{1 *}$

${ }^{1}$ Department of Breast surgery, The First Affiliated Hospital of Xinjiang Medical University, China

${ }^{2}$ Department of Neurosurgery, The First Affiliated Hospital of Xinjiang Medical University, China

Submission: May 20, 2019 ; Published: May 23, 2019

*Corresponding author: Dilimulati Aisimutula, Department of Breast surgery, The First Affiliated Hospital of Xinjiang Medical University, China Guo Chenming, Department of Breast surgery, The First Affiliated Hospital of Xinjiang Medical University, China

\begin{abstract}
Gigantomastia is a particular abnormal physical condition of the breast connective tissues, which cannot seen very often. Gigantomastia is often associated with pregnancy and characterized by a diffuse, disproportionate and excessive growth of both breasts in many cases. It can generate both physical and psychosocial disabling to the patient. The etiology is not entirely understood, although hormonal changes during pregnancy are assumed responsible for this medical condition. Since the pathology of this disease is extremely rare and has seldom been described, this report present a case of 37-years-old woman in her seven months pregnancy with a bilateral gestational gigantomastia associated with breast lumps. This report follows the patient from her primary diagnosis until the completion of final treatment.
\end{abstract}

Keywords: Breast; Gestational gigantomastia; Breast lumps

Abbreviatations: GG: Gestational Gigantomastia; GAD: Generalized Anxiety Disorder

\section{Introduction}

Gigantomastia in pregnancy, also called as gestational gigantomastia (GG) and gravid macromastia, is a rare medical condition of the breast connective tissues, often associated with pregnancy and characterized by a diffuse, disproportionate and excessive growth of both breasts. (1.5kg) [1]. In 1648, gestational gigantomastia was first reported by Palmuth and since then less than 100 cases about gigantomastia have been reported in the literature [2]. It is a extremely rare mammary gland disease with a prevalence of about 1 case per 100000 pregnancies [3]. In 2011, Dafydd et al. [4] Clearly defined gigantomastia as excess breast tissue that contributes $3 \%$ of a patient's total body weight. It can generate both physical and psychosocial disabling to the patient. This disease not only directly affect the patient's quality of life but also exert a strong influence to the progression of patient's pregnancy [5]. In addition to social and emotional disability, it can also lead to a lot of physical symptoms as well, which include continue breast pain, breast skin infection, severe ulceration, postural difficulty and terrible back pain. It can even result in chronic traction and hence causing temporary or permanent damage to fourth, fifth, or sixth intercostals nerves mainly manifests as the form of loss of nipple sensation, further more promoting breast infection and ulceration [1].

\section{Case Presentation}

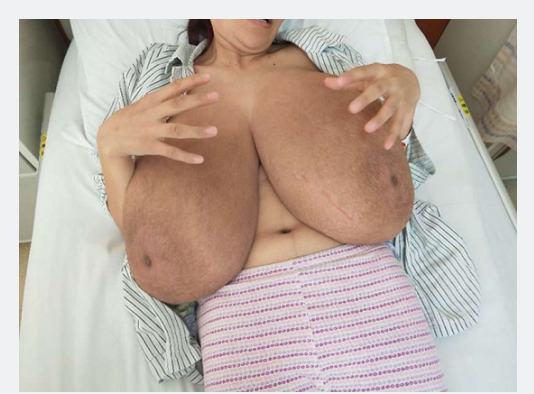

Figure 1: Frontal view, appearance of gestational gigantomastia. Note the excessive breast size that prevented the patient from moving around or changing position in bed. 
In March 2018, a 37-year-old women applied to The First Affiliated Hospital of Xinjiang Medical University with enlargement of breast tissue. This abnormal enlargement of both breasts started at 15 weeks' gestation and continued to growth rapidly as the patients pregnancy progressed. In addition to the enlargement of both breasts, the patient also complained of a terrible pain in the breasts and back (Figures 1\&2). The patient was also complaining on severe dyspnea, moving difficulties and difficulty in meeting basic daily needs. This is the first pregnancy of the patient and she never experienced any abnormal size of the breasts before. During her hospitalization, the patient developed difficulty in breathing, comfortlessness, and generalized anxiety disorder(GAD). This pathological condition was a consequence of the excessive growth of breast volume, which kept her confined to bed, especially in her spine, resulting from the dorsal decubitus position that she was obliged to adopt because of the size of her breasts, which prevented her from normal walking or even changing position in bed. Because of her distress, she decided to interrupt her pregnancy and perform a odinopoeia at 27 weeks and 5 days of pregnancy. Her past medical history was unremarkable. Past surgical history included only a odinopoeia at 27 weeks in The first affiliated hospital of xinjiang medical university for worsening dyspnea. She did not have any history of chronic disease, drug use. Family history was negative for breast hypertrophy. Surgical therapy was strongly demanded by the patient and her relatives.

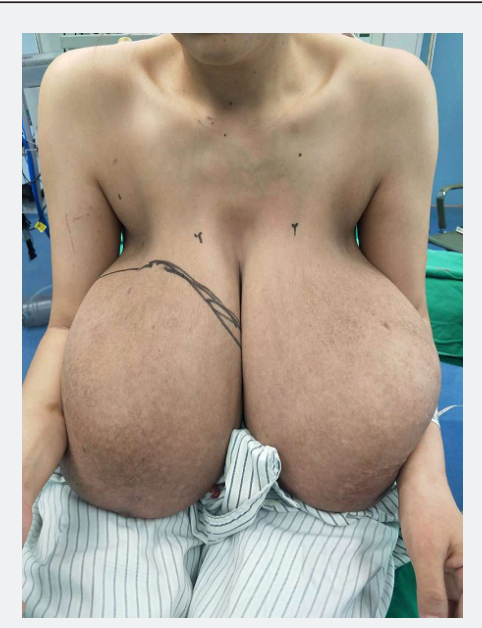

Figure 2: Frontal view, appearance of the breasts before the surgery.

The patient reported that her breast size prior to pregnancy was about 34B and now estimates her breasts are 5 times larger during this pregnancy. In physical examination, weight was $74 \mathrm{~kg}$, height was $165 \mathrm{~cm}$, and BMI(body mass index) was 27 . Both breasts were hard and there was not any mass by palpation. Breast skin was tense; superficial veins were prominent and dilated. The patient did not have fever and there was not any erythema, warmth, or ulceration on breast skin. Bilateral galactorrhea was observed. There was a bilateral axillary lymphadenopathy (hard with certain mobility of lymph nodes) but no su- praclavicular area lymphadenopathy. Blood test results indicated the following hormone levels: prolactin $202.61 \mathrm{mIU} / \mathrm{L}$,oestradiol $753.15 \mathrm{pmol} / \mathrm{L}$, progesterone $2.41 \mathrm{mg} / \mathrm{mL}$, luteinizing hormone 5.88IU/L, and follicle-stimulating hormone 3.5IU/L. Complete blood count, erythrocyte sedimentation rate (ESR), inflammation c-reactive protein (CRP), transaminase (GPT and GOT), $\gamma$-GT, thyroid stimulating hormone (TSH), were all within normal limits. Breast ultrasonography result showed multiple hypoechogenic masses with posterior enhancement in the axillary tail of both breasts and in the inner lower quadrant of the right breast (RLIQ). Ultrasound also demonstrated severe diffused breast edema including the cutaneous tissue, inflammation signs, lowgrade lymphatic dilatation, Edema of the skin, and couldn't eliminate underlying malignancy. Percutaneous fine-needle aspiration and core biopsy analysis of the breast lumps demonstrated atypical epithelial hyperplasia. chest X-ray (CXR), abdominal scan, Cranial MRI showed no abnormalities. After the ultimate evaluation simple mastectomy was recommended. on request of the patient, the patient was submitted to simple right mastectomy on March 26th, 2018 (Figures 3,4), which proceeded without any complications. After about 2 months the patient was submitted to simple left mastectomy on May 16th,2018, the procedure was completed without any complication. The biopsies reverled fibrous fibroadenomas, sinbehng adenopathy, myxoid degeneration of the stroma, ductal and lobular hyperplasia, and mammary duct cystic dilation (Figure 5). According to the histology of the lumps, a confirmed diagnosis of fibroadenoma was made. Besides, there was no obvious chronic inflammatory cellular infiltrate or any histologic evidence of malignancy. The patient was satisfied with the effect of each surgery that we performed (7.93kg and $8.10 \mathrm{~kg}$ of tissue were removed from the right and left breasts, respectively). From both clinical and psychological point of view, the patient is currently in fairly good health. After 13 months of breast surgery, there was no relapse. The patient's follow-up health assessments went smoothly. After receiving written and oral informed consent from our patient, we made the decision to presenting this case report.

\section{Discussion}

Gestational gigantomastia is a painful disease of unknown etiology, which psychologically and physically debilitating for patients. Risk factors of gestational gigantomastia are not fully known, but the probability of occurrence of gestational gigantomastia is higher in Caucasian and multiparous women [6]. Gestational gigantomastia can happen during any pregnancy [7]. A prior history of gestational gigantomastia raised the risk for the condition in subsequent pregnancies [8-11]. In spite of the etiology and pathogenesis of gestational gigantomastia still remain elusive [12], but plentiful theories have been proposed, including excessive release of estrogen or prolactin during pregnancy, disorder of hormone receptor sensitivity, and potential autoimmune disease triggered by pregnancy [13]. Prolactin is the most important hormone among the rest hormones shown as a tar- 
get in etiology. Besides this, other hormones such as estrogen, progesterone, growth hormone, thyroxine, cortisol, insulin and human placental lactogen are also deduced that have an effect on pathogenesis of gestational gigantomastia [14]. There are also several reported cases of penicillamine induced gigantomastia with subsequent treatment with danazol [15-18]. For purpose of eliminate underlying disease processes which can present as gigantomastia, a full workup including hematology, endocrinology, and biopsy should be completed.

Since most cases of gigantomastia occur during puberty or pregnancy, one possible etiology is the excessive production of estrogen or prolactin $[19,20]$. However, some cases of gigantomastia have occurred in a setting of normal estrogen and prolactin hormone levels [21]. Even in a setting with high estrogen and prolactin hormone levels, it is unclear whether such levels, normally elevated in pregnancy, are the pathogenic factors of gigantomastia $[22,23]$. In this case report patient's estradiol hormone, prolactin hormone, thyroid stimulating hormone, luteinizing hormone, follicle-stimulating hormone levels were all within normal limits, other lab investigations were also normal. Cases of gigantomastia with normal hormone levels may be explained by enhanced hormonal sensitivity in the breast $[19,24]$.

The association of gestational gigantomastia with bilateral breast lumps is truly exceptional. Rare cases of gigantomastia associated with breast lumps have been reported, but only under circumstance of unilateral gigantomastia [25-27]. This case report describes a case of bilateral gestational gigantomastia with bilateral breast lumps. Due to the rapid rate of breast enlargement, gestational gigantomastia presents Similarly to malignant breast disease such as a phyllodes tumor $[8,10]$. When making a diagnosis of benign gestational gigantomastia, other disease processes must be considered and eliminated first of all. Differential diagnoses for gestational gigantomastia with normal prolactin levels may include infectious mastitis, juvenile breast hypertrophy and normal pregnancy changes, other benign breast conditions such as fibrocystic change or fibroadenoma, adenosis of mammary glands, and underlying malignancy.

Treatment for gestational gigantomastia has varied on a case-by-case. Some experts suggested that estrogen receptor sensitivity to prolactin might have accounted for gestational gigantomastia. Conservative measures such as proper brassiere support, good skin care or hygiene, analgesia treatment, and Daily adequate nutrition [28]. Up to date, the most widely used medicine for the treatment of gestational gigantomastia is bromocriptine mesylate, yet results have been variable. Anecdotal evidence suggests that bromocriptine mesylate therapy during pregnancy may cause fetal intrauterine growth retardation(IUGR) and fetal distress; The most successful therapy for gestational gigantomastia is surgical intervention treatment [29,30]. The further complications such as puerperal mastitis can be prevented by surgery during the immediate postpartum period . Surgical treatment should be considered in cases of enormous hypertrophy in which reduction is unlikely successful with bromocriptine mesylate therapy alone $[7,31]$ or in cases of continued enlargement despite Conservative medical therapy [2]. Advantage of simple mastectomy over reduction is less blood loss during the procedure, which is significant considering patients with gestational gigantomastia have engorged and friable blood vessels $[2,7,32]$.

\section{Conclusion}

This case report describes the rare condition of gestational gigantomastia which associated with multiple fibroadenomas; however, the role of such fibroadenomas in the genesis or exacerbation of gigantomastia remains to be determined. lack of information about the patient's hormone levels in early pregnancy is a limitation of this case report. The availability of this data in future cases could help more clinicians make the appropriate decision to choose treatment with bromocriptine before delivery, and could also facilitate the diagnosis and differential diagnosis of this condition from other breast diseases that present similar symptoms.

\section{Consent}

The patient described in the case report has given informed consent for the case report to be published.

\section{References}

1. Dancey A, Khan M, Dawson J (2008) Gigantomastia a classification and re- view of the literature. J Plast Reconstruct Aesthet Surg 61(5): 493502 .

2. Vidaeff AC, Ross PJ, Livingston CK, Parks DH (2003) Gigantomastia complicating mirror syndrome in pregnancy. Gynecol 101(5): 11391142 .

3. Antevski BM, Smilevski DA, Stojovski MZ, Filipovski VA, Banev SG, et al. (2007) Extreme gigantomastia in pregnancy: case report and review of lit- erature. Arch Gynecol Obstet 275(2): 149-153.

4. Dafydd H, Roehl KR, Phillips LG, Dancey A, Peart F, et al. (2011) Redefining gigantomastia. J Plast Reconstr Aesthet Surg 64(2): 160163.

5. Andre' FS, Chocial AC (2010) Treatment of gigantomasty. Revista Brasileira de Cirurgia Pla'stica 25(4): 657-662.

6. Moss WM (1968) Gigantomastia with pregnancy A case report with review of the literature. Arch Surg 96(1): 27-32.

7. Antevski B, Jovkovski O, Filipovski V, Banev S (2011) Extreme gigantomastia in pregnancy: case report-my experience with two cases in last 5 years. Arch Gynecol Obstet 284(3): 575-578.

8. Ezem BU, Osuagwu CC, Opara KA (2011) Gestational gigantomastia with complete resolution in a Nigerian woman. BMJ Case Rep.

9. Lokuhetty MDS, Saparamadu PAM, Al-Sajee DMA, Al-Ajmi R (2011) Gigantomastia in pregnancy with an accessory axillary mass masquerading as inflammatory carcinoma. Diagn Cytopathol 39(2): 141-143.

10. Sakai T, Fujimori M, Tominaga Y, Kanai T, Ito KI, et al. (2005) A case of unilateral gravid macromastia in 23-year-old japanese woman associated with elevated serum ca19-9. Breast Cancer 12(3): 238-242.

11. Villanueva E, Shah N, Geer EB (2015) A case of post-partum gigantomastia treated successfully with bromocriptine. in Proceedings 
of the Endocrine Society $97^{\text {th }}$ Annual Meeting Expo Santiago Calif USA, USA.

12. Jido TA, Mohamed AZ, Alhasan SU (2006) Gigantomastia complicating pregnancy: a case report. Niger J Med 15(2): 167-169.

13. Leis SN, Palmer B, Ostberg G (1974) Gravid macromastia. Case report. Scand J Plast Reconstr Surg 8(3): 247-249.

14. Boyce SW, Hoffman PG, Mathes SJ (1984) Recurrent macromastia after subcutaneous mastectomy. Ann Plast Surg 13(6): 511-518.

15. Thew DC, Stewart IM (1980) D penicillamine and breast enlargement Annals of the Rheumatic Diseases 39(2): 200.

16. Passas C, Weinstein A (2010) Breast gigantism with penicillamine therapy. Arthritis Rheumatism 21: 167-168.

17. Rooney PJ, Cleland J (1981) Successful treatment of D-penicillamineinduced breast gigantism with danazol. BMJ 282: 1627-1628.

18. Taylor PJ, Cumming DC, Corenblum B (1981) Successful treatment of D-penicillamine-induced breast gigantism with danazol. Br Med J (Clin Res Ed) 282(6261): 362-363.

19. Wølner-Hanssen P, Palmer B, Sjöberg NO, Stedt B (1981) Gigantomastia. Acta Obstet Gynecol Scand 60(5): 525-527.

20. Parham kj (1961) Gigantomastia. Report of a case. Obstet Gynecol 18: 375-379.

21. El BS, Pitkanen J, Hassonah M, Al SM (1997) Emergency mastectomy in gigantomastia of pregnancy: A case report and literature review. Ann Saudi Med 17(2): 220-222.

22. Sharma K, Nigam S, Khurana N, Chaturvedi KU (2004) Unilateral gestational macromastia-a rare disorder. Malays J Pathol 26(2): 125128.

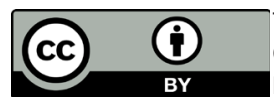

This work is licensed under Creative Commons Attribution 4.0 License DOI: 10.19080/JGWH.2019.15.555911
23. Kaviani A, Hashemi E, Fathi M, Rabbani A (2006) Pregnancy-Induced Gigantomastia in a 19-Year-Old Woman. Breast J 12(5): 495-496.

24. Nutan A, Alka K, Anjali G, Bhatla N (2002) Management of gigantomastia complicating pregnancy. A case report. J Reprod Med 47(10): 871-874.

25. Tantrige PM, Hassanally D (2011) Recurrent giant juvenile fibroadenomas with hemihypertrophy. Breast Dis 33(1): 41-44.

26. Wolfram D, Behensky H, Piza-Katzer H (2009) Unilateral gigantomastia related to juvenile fibroadenoma with idiopathic thoracic scoliosis. J Pediatr Adolesc Gynecol 22(3): e25-e27.

27. Hynes SO, McLaughlin R, Kerin M, Rowaiye B, Connolly CE, et al. (2012) A unique cause of a rare disorder, unilateral macromastia due to lymphangiomatosis of the breast: a case report. Breast J 18(4): 367370 .

28. Rezai S, Nakagawa JT, Tedesco J, Chadee A, Gottimukkala S, et al. (2015) Gestational Gigantomastia Complicating Pregnancy: A Case Report and Review of the Literature. Case Rep Obstet Gynecol 2015: 892369.

29. Vinicki JP, Gonzalez CN, Dubinsky D, Nasswetter G, Cardinal LH, et al. (2015) Gestational gigantomastia in autoimmune diseases. J Clin Rheumatol 21(2): 110-112.

30. Shoma A, Elbassiony L, Amin M, Zalata K, Megahed N, et al. (2011) Gestational gigantomastia': a review article and case presentation of a new surgical management option. Surg Innov 18(1): 94-101.

31. Wolf Y, Pauzner D, Groutz A, Walman I, David MP, et al. (1995) Gigantomastia complicating pregnancy: case report and review of the literature. Acta Obstet Gynecol Scand 74(2): 159-163.

32. Bloom SA, Nahabedian MY (2008) Gestational macromastia: a medical and surgical challenge. Breast J 14(5): 492-495.

\section{Your next submission with Juniper Publishers will reach you the below assets}

- Quality Editorial service

- Swift Peer Review

- Reprints availability

- E-prints Service

- Manuscript Podcast for convenient understanding

- Global attainment for your research

- Manuscript accessibility in different formats

( Pdf, E-pub, Full Text, Audio)

- Unceasing customer service

Track the below URL for one-step submission https://juniperpublishers.com/online-submission.php 